\title{
THE XII CENTURY TOWERS, A BENCHMARK OF THE ROME COUNTRYSIDE ALMOST CANCELLED: THE SAFEGUARD PLAN BY LOW COST UAV AND TERRESTRIAL DSM PHOTOGRAMMETRY SURVEYING AND 3D WEB GIS APPLICATIONS
}

\author{
L. Barelli ${ }^{1}$, P. Paolini ${ }^{1,} *$, G. Forti ${ }^{2}$ \\ ${ }^{1}$ Dept. of History, Representation, and Restoration of Architecture (D.S.D.R.A), "SAPIENZA" University, Rome, Italy - \\ (Lia.Barelli, Priscilla.Paolini)@uniroma1.it \\ ${ }^{2}$ ESRI Italia, Rome, Italy - gforti@esriitalia.it
}

\section{Commission II}

KEY WORDS: XII century towers, Rome Mid-Age countryside, Cultural Heritage preservation, close-range photogrammetry, UAV photogrammetry, integrated survey, low-cost action camera, GPS, Web GIS 2D and 3D.

\begin{abstract}
:
"Giving a bird-fly look at the Rome countryside, throughout the Middle Age central period, it would show as if the multiple city towers has been widely spread around the territory" on a radial range of maximum thirty kilometers far from the Capitol Hill center (Carocci and Vendittelli, 2004).

This is the consequence of the phenomenon identified with the "Incasalamento" neologism, described in depth in the following paper, intended as the general process of expansion of the urban society interests outside the downtown limits, started from the half of the XII and developed through all the XIII century, slowing down and ending in the following years. From the XIX century till today the architectural finds of this reality have raised the interest of many national and international scientists, which aimed to study and catalog them all to create a complete framework that, cause of its extension, didn't allow yet attempting any element by element detailed analysis. From the described situation has started our plan of intervention, we will apply integrated survey methods and technologies of terrestrial and UAV near stereo-photogrammetry, by the use of low cost drones, more than action cameras and reflex on extensible rods, integrated and referenced with GPS and topographic survey. In the final project we intend to produce some 3D scaled and textured surface models of any artifact (almost two hundreds were firstly observed still standing), to singularly study the dimensions and structure, to analyze the building materials and details and to formulate an hypothesis about any function, based even on the position along the territory. These models, successively georeferenced, will be imported into a 2D and 3D WebGIS and organized in layers made visible on basemaps of reference, as much as on historical maps.
\end{abstract}

\section{INTRODUCTION}

\subsection{The State of the Art}

The Middle Age towers (as isolated structures or as part of farmhouses), stand on the Rome countryside landscape as a representative witness of an epoch, being until today the survived architectural expression and core of the general process of expansion of the urban society interests, outside the downtown limits. Since the half of the XII century the blowing up of the Rome society and its dynamic economy, brought the urban lay and ecclesiastical élite to the realization of many financial investments along the countryside area, as a consequence of the local disappearing of any prior and stable residency. Therefore it resulted into the merging into a single property of wide extensions of land, seen since then as productive entities, exclusively dedicated to cereal crops and cattle breeding. There occurred the functional creation of farmhouses (cited as tower with land properties-turris cum tenimenta first and farmhouses-casali later) and castra, two types changing one into the other as much as a more defensive role was required, gradually moving far from Rome city limits, therefore representing the solution to control those huge economical investments, destined to persist for a very long time. Scholars from our Department of History, Representation and Restoration of Architecture of SAPIENZA University in Rome (DSDRA), through the integration of competences in History, Restoration, Survey and Modelling of Architecture, since time investigate on such phenomenon, starting from archival, historical and bibliographic research, till the direct analysis of the techniques and building materials, as of the related state of degradation, so as through the study of the architectural shape and structure. Since the early eighties of the twentieth century till today, even the Capitol Superintendence of Rome by publishing the:" Historical, Archaeological, Monumental Map of the roman Suburbs and Countryside", linked to the new General Town Plan (P. R. G.), showed its interest in the safeguard of the more at risk minor Cultural Heritage assets, such intending towers, farmhouses and historical properties.

A land Census organized in typological categories of 8000 goods and a second one inclusive of archival, bibliographic and cartographic references are part of the newly created GIS, merged to the Informative system of Museums, Art and Territory called SIMART. Specialists from the Cartography laboratory of the Rome Superintendence provided to insert them

* Corresponding author 
into a WebGIS, where all the goods descriptive cards were linked together, either 2D vector format data or maps, but all accessible actually via intranet only (Marcelli et al., 2014).

Despite these activities and first efforts, no protective or satisfactory action was ever performed by any of the competent bodies yet, recently resulting in the partial or total loss of some artifacts, getting into progressive worst conditions and collapse.

\section{THE HISTORICAL FRAME}

\subsection{The Incasalamento Dynamics and Characters}

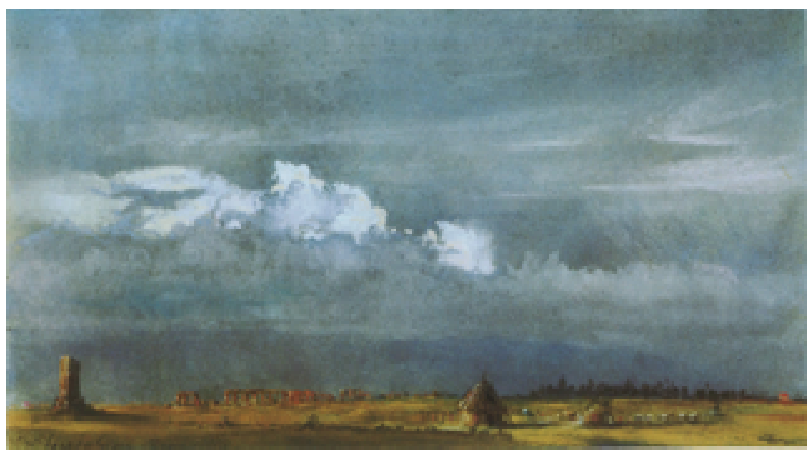

Figure 1. E. Gioia (1862-1937) campagna romana

The Roman Campagna (countryside) ${ }^{1}$ was characterized in the Middle Ages by a large number of settlements, widespread and extensive (up to hundreds of hectares), linked or to the control and jurisdiction of the territory, the castra, or to its agricultural management, the casali (farm hamlets). This latter term meant a farm, mainly for cereal production, where subsisted a small resident population with the addition of seasonal workers. It is not easy, based solely on buildings, to distinguish between casali and castra, since both were characterized by fortified elements and sometimes by non-dissimilar extensions. In fact, to understand the nature of the settlement, the elements to be considered were not the edified parts, but the legal status of the residents, which in the castra was based on feudal ties, and the cultivated land might even not to be owned by the lord, whereas in casali workers were the employees of the proprietor. For these reasons, the lord of a castrum benefited from tax levied on the population, while in casali gain was derived from production. Regarding the geographical distribution, historians have (in an artificial manner) identified three zones within the roman Countryside having the Urbe (Carocci and Vendittelli, 2004) as their centre: the first, beyond the vineyard area around the Aurelian walls, was six-to-seven kilometres wide arable land, occupied by farmhouses and other smallholdings; the second, of four-to-six kilometres, was characterized by the copresence of castra and casali and finally the third, where the castra clearly predominated. In the last two zones there were also a few villas and burgi, a type of settlement that was dying out. Most of these settlements originated in the 12th and 13th centuries thanks to favourable political and economic circumstances that allowed noble and wealthy Roman families and ecclesiastical institutions to occupy and "manage" the outlying territories of the city. Often linked to pre-existing Roman-era settlements, castra and casali were re-used, either

\footnotetext{
${ }^{1}$ This definition signifies "the area between the vineyards of the suburbs and the first castles and villages that survive from abandonment in the late Middle Ages" (Carocci and Vendittelli 2004: 8).
}

directly, by building them over the ancient remains for elevation and solidity, or by recovering construction materials, or by exploiting accessory parts such as cisterns. In the outbuildings there are in fact wells, cisterns, watering holes, canals and fishing ponds, more or less deriving from the reuse of ancient structures. These latter structures in particular show the great importance of water for such settlements. The need for water reserves for agricultural activities and everyday life, in fact, determined the site where many of them were located, more densely in the south-east area of the suburb, full of watercourses, including the Marrana creek, actually the union of more ancient waters. An important element in choosing the location for a settlement was also the presence of spring water, often acidic, as some of the documented place names indicate (Acqua Bullicante - Bubbling Water, Acqua Sotterra Underground Water, Acqua Puzza - Smelly Water, etc.), its presence allowing for industrial activities such as milling, wool fulling, etc. A fairly indicative picture of the spread of medieval settlements in the roman Campagna is provided in the map by Eufrosino della Volpaia (Map of the Roman Campagna in Paul III's time, 1547), though it reflects a later situation (Figure 2).

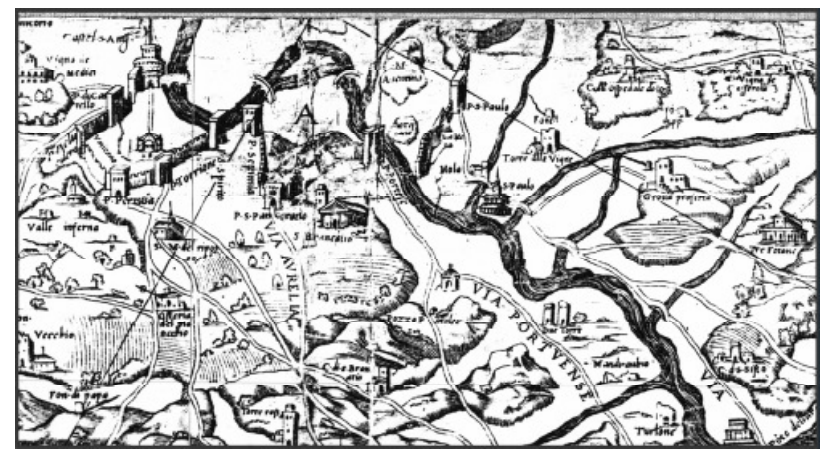

Figure 2. Eufrosino della Volpaia, 1547, detail of sheets 2 e 3

In fact, it is important not to confuse the original use and management of these settlements with practices and situations of different geographies and later centuries.

This particular organization of the territory, which has no contemporary equal, has attracted the attention of many scholars even in recent times, as much research has been devoted to finding and interpreting any written sources as to investigating the surviving physical structures ${ }^{2}$. Nonetheless, many aspects have still to be clarified or explored. A highly characteristic architectural element in almost all such settlements is the tower - turris - usually very tall and generally alone (paired towers are rare). It is worth remembering that before the appearance of the term casale in notarial deeds, such settlements were called turris, a term that meant not a single structure but the group of buildings to which it belonged. At least until the last century urbanization, the landscape around the Urbe was clearly marked - in addition to Roman ruins distinguished by aqueducts - by abandoned and ruined towers, visible from a considerable distance. These towers could be isolated structures, usually surrounded by a brick enclosure (redimen), or part of groups of buildings of a certain complexity, like a real castrum or casale.

\footnotetext{
${ }^{2}$ Noted studies include, in addition to references in the many works by Giuseppe Tomassetti on the Roman Campagna, by Jean Coste and his students, the reports of surveys conducted by the British School at Rome, the writings of Giovanni Maria De Rossi, and the most recent investigations by Sandro Carocci, Marco Vendittelli and Daniela Esposito.
} 
The corpus of these is fairly homogeneous in terms of form, size, and construction, and it should be noted that, in these respects, it does not appear significantly different from similar structures in the city, although obviously different in context and relationship ${ }^{3 .}$ The towers of the Roman Campagna were generally square or quadrangular (there are exceptions, though rare), and had sides from 4 to 8 metres long and thick walls, also linked to height, ranging from 10 to 30 metres. The internal divisions were generally made up of barrel- or cross-vaulted structures on the bottom and top level, with wooden floors in between (Figure 3).

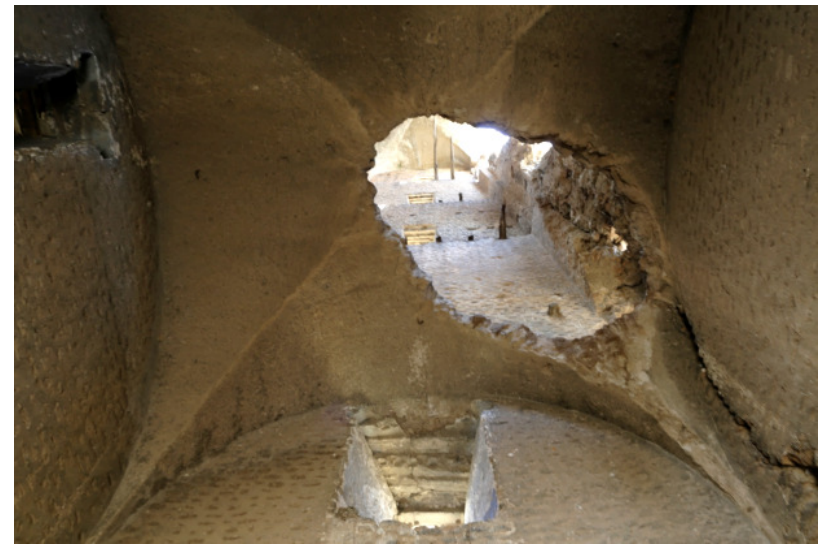

Figure 3.T. Maggiore crossed vault and middle wooden ceilings

The latter can also be found on the lower level. The roof was terraced, with exterior rainwater spouts. Generally the parapets had crenellations. The landings between floors were very high, which involved extremely steep vertical connections, in some cases real runged ladders. Access was often directly from the first floor with more or less removable ladders.

Windows were very rare, the Illumination of the lower part came from slits high above the floor, so the light spread downwards, aided by embrasures. In the upper parts, however, there were real windows for looking out of, made up of rectangular compartments with jambs, sills and stone arches, usually white marble, often overlaid by small brick drainage arches. In some cases there are external storm drains on stone shelves, mostly for sewage runoff. Some interesting interior elements are niches for objects (especially lanterns) and fireplaces, but judging from examples that remain they seem rather rare. The function, or primary functions, of these towers remains a matter of discussion.

One was undoubtedly defence/offense in cases of extreme necessity ${ }^{4}$. Housing seems unlikely, due in part to the lack of features such as chimneys, needed for both cooking and heating, as well as the inconvenience of vertical, often ephemeral connections. Moreover, it could be that in urban complexes the tower was an indivisible property of the family group, while the real families of the clan lived in neighbouring homes. Although more strictly utilitarian functions probably existed in some

3 See Carocci and Vendittelli's studies on the urban environment.

${ }^{4}$ There is documentation of the offensive/defensive use of the towers in the urban castra, which led to the order by the Senator of Rome Brancaleone of Andalò, who in 1257 had some one-hundred baronial towers torn down following the struggles that developed in the city. tower environments, which could serve as warehouses, an important role of these structures was undoubtedly symbolic, a manifestation of power and capacity and a flourishing economy, as in many urban cases. In the Campagna, they were probably placed for visibility, in the area they belonged to, both for those overseeing from the tower and as a visible point of reference for those in the countryside. Control could extend to those coming from outside, as well as to workers and the state of the crops. According to historians, the towers of the Roman Campagna do not seem to have had a "semaphorical" function, that is, they were not a network of connected watchtowers, as was the case in other Italian regions.

\section{THE SURVEY WORKFLOW}

\subsection{The Base Plan}

In this last decade, photogrammetry for the survey of Cultural Heritage has reconquered, with the advent of the digital era, its leading role in many research activities, being in its whole a non-contact testing method and a low cost procedure easy to apply, so for the short operating time requested, as for the involving of low cost instruments and semi-automatic software procedures (Grussenmeyer et al., 2008). Even more with the involvement of Unmanned Aerial Vehicles systems, nowadays so diffused that often take the place of classical aerialphotogrammetry made by airplane or helicopter (Murtiyoso et al., 2017).

For these reasons this has been the technology we firstly applied on the tenimentum Tusculanum, the geographic area from which has started our work (Figure 4).

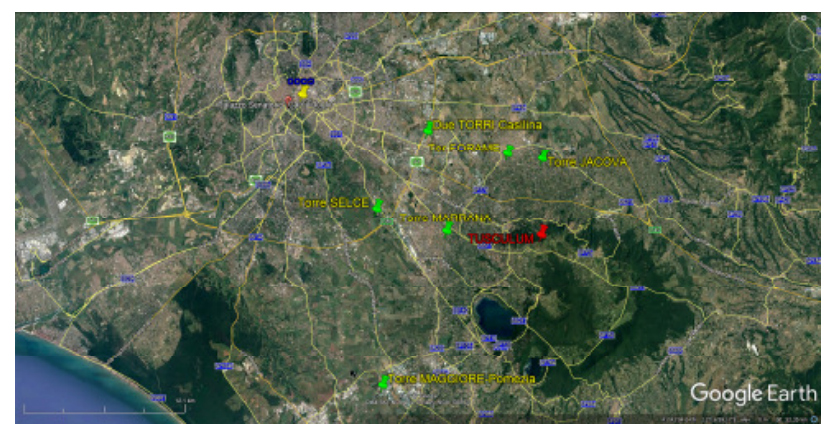

Figure 4. The tenimentum Tusculanum towers

This stripe of territory at south east of Rome, was originally part of the ancient roman municipality of Tuscolo, then conquered and destroyed by romans in 1191, when passed under the control of the Church. Since then it began the exploitation of this huge extension of land, parted between the Rome clerical bodies and the lay élite mainly aiming at controlling it. In this area as a peculiarity, despite its distance from Rome, no defensive need is shown by the prevalent presence of casali and towers, so that our research was firstly focused here, applied on a first group of towers selected for their specific and basic type, described as: "tower with redimen (boundary wall)", a configuration diffused since the XII century. The stereophotogrammetric surveying technology and methods resulted useful in general, thanks to the high resolution of the textured mesh model of the outside and inside vertical walls and basement of each artifact, (resulting in detailed descriptions of windows, loopholes, beams and scaffoldings traces), obtained by stitching shootings taken from ground stations, using different types of cameras mounted on tripod or rod. More was 
done by adding aerial shooting, performed by UAV systems, and then georeferenced, to survey all the building when visible by far, or only to include in each 3D surface model the top parts or roofs of any tower, a detail usually missing in any architectural and archaeological survey cause of the impossibility of getting Nadir views from ground stations. Aiming to collect a complete database including all the middle age finds of the Rome countryside, we cannot forget that any tower or farmhouse or castrum has lived its own life and has such a shape, position, materials, details and degradation to have a character to be considered by itself and so surveyed with a subjective integration of techniques. Answering to this premise, these two low cost survey procedures were differently applied and integrated, each one working as a useful example for fastening the future complete work. The georeferencing of each model was realized indirectly to grant high accuracy, as stated (Shahbazi et al., 2015; Lachat et al., 2017), by the application of total stations and GPS systems and allowed the final models to be exported as, either .KMZ format to be imported on Google Earth, or .LAS format to be loaded into the 2D and 3D GIS and into the WebGIS applications.

\subsection{Technologies and Method}

The potential of small drones for heritage management (Stek, 2016) has been underlined by the application of different types of UAV systems on towers, aiming to experiment the results of either automatic or manual flight mode and see the differences in resolution and 3D model details, so to defining more optimal methods (Mouget and Lucet, 2014). The first applied was an Aeromax X4, a Rotary-wing quadcopter composed by a whole carbon class 3 structure, beech blades, a Pixhawk 16 bit flight controller hardware, a 2 axis servo gimbal, it performs a maximum time of flight of 25 minutes at $3.90 \mathrm{~kg}$ of full payload, mounting a mirrorless Camera Sony Alpha 5100, weight 283 gr, with APS-C CMOS sensor, 24,7 Mpxels, 24,3 effective, $(6058 \times 4012-23,3 \times 15,6 \mathrm{~mm}-1 \mathrm{pxl}=0.0039 \mathrm{~mm}-100$ - 25600 ISO, E PZ 16-50mm Lens (crop factor 1.53 - 24.5 -

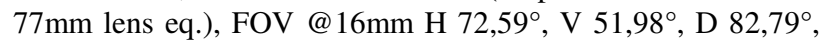

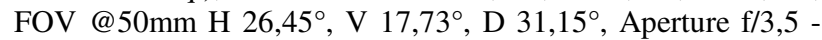
5,6 (weight $125 \mathrm{gr}$ ), minimum focus distance $0,25 \mathrm{~m}$, Optical Steady Shot, file format jpeg large and Raw(.ARW -Alpha RaW) (Figure 5).

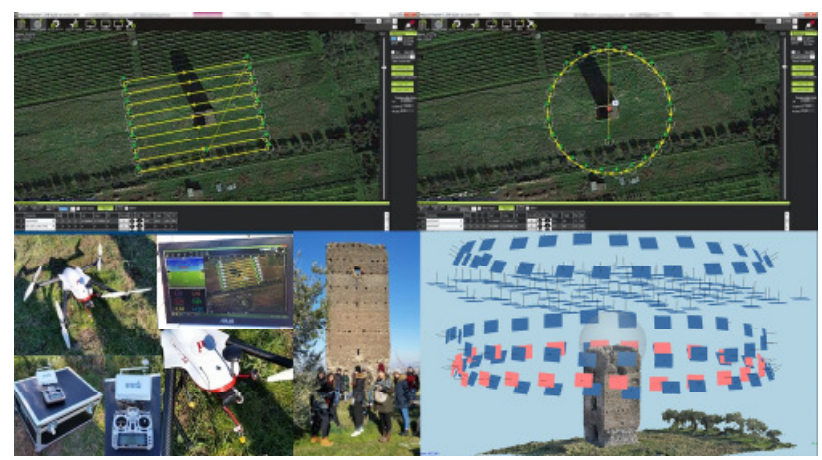

Figure 5. UAVs survey and PhotoScan final alignment

The drone flight is controlled by a ground datalink Real Time Kinematic that triangulates the in-flight position improving GPS data accuracy. The Ground Controller $(2.4 \mathrm{GHz})$ uses a full feature, free, open-source Mission Planner application, that allows to control and tune the drone components performance and to plan and save in advance any shooting mission to reload and apply it autonomously on field. While it monitors the vehicle's status, it records telemetry logs, to view and analyze them all.

The alternative was to use a Phantom 4 Pro (Ph4Pro), rotary wing quadcopter, weight 1388 gr at full payload, max flight time 30 minutes circa, Satellite Positioning Systems GPS/GLONASS, Gimbal 3 axis (roll, pitch, yaw) brushless, camera Sensor 1" CMOS (crop factor 2,7x), effective 20 Mpxls, stabilized, ISO 100 - 3200 (Auto) 100 - 12800 (Manual), $8,8 \mathrm{~mm}$ Lens ( $24 \mathrm{~mm}, 35 \mathrm{~mm}$ equivalent), FOV $84^{\circ}$ diagonal, Aperture $f / 2,8-f / 11$ auto focus at $1 \mathrm{~m}-\infty$, file format Jpeg large and Raw DNG. As a third instance we applied a DJI Phantom $4(\mathrm{Ph} 4)$ rotary wing quadcopter, same weight and general characters as the second except for the camera Sensor 1/2.3" CMOS, effective 12,4 Mpxls, 3.5mm Lens (20mm, $35 \mathrm{~mm}$ format equivalent), FOV $94^{\circ}$ diagonal, Aperture $\mathrm{f} / 2.8$ focus at $\infty$, file format Jpeg large and Raw DNG. Both use a Ground Remote controller at 2,4GHz, and the IOS systems app GS Pro (Ground Station Pro) able to control or plan automatic (GPS connected) or manual (Attitude) flights, to set flight path with camera set parameters and chose a specified flight zone even marking the zone boundaries.

About the terrestrial photogrammetry we used an action camera Xiaomi YI 4k, Sony image sensor IMX377, 1/2.3", 12 megapixels $(4000 \times 3000)$ CMOS with Exmor R ability, $1 \mathrm{pxl}=0.0055 \mathrm{~mm}, 2.66 \pm 5 \% \mathrm{~mm}$ Lens $(14 \mathrm{~mm}$, equivalent $35 \mathrm{~mm})$, Aperture f/2.8, FOV D. $155^{\circ}$, built-in 3 axis gyroscope and 3 axis accelerometer. It applies a cross-border compensation algorithm, has an auto Low Light system, allows to apply the Lens Distortion Correction, ISO 100-800, EV (Exposure Value compensation) $-2.0,+2.0$, metering mode Spot and Center, Raw photo format. The action camera was mounted on a 13.5 meters extensible carbon rod (Neutech-ON AIR C135, 7 sections, 3,10 $\mathrm{kg}$ ) and stabilized by a specific tripod; any shooting set was performed by the YI Action App on mobile, wifi connected.

As an alternative the Canon 5D Mark III produced qualitative results, CMOS sensor $22.3 \mathrm{Mp}(5760 \times 3840)$ full frame $(36 \times 24 \mathrm{~mm})$, EF $24 \mathrm{~mm}$ f $/ 1.4 \mathrm{~L}$ II USM lens, FOV D. $84^{\circ}$, H.73,74 ${ }^{\circ}$, V.53, $13^{\circ}$, , weight $650 \mathrm{gr}$, Jpeg large and Raw format. The shooting was realized mounting the camera on aluminum 5 meters telescopic rod, triggered by wifi connection using the Camera Remote App on mobile. All the survey models have been scaled and georeferenced by the import of geographic coordinates. The GPS antenna, Geomax, Zenith 35 Pro, helped specifically, thanks to its digital inclinometer that works on rod over the pole at $15^{\circ}$, in single mode and at $30^{\circ}$, in dual mode (GNSS Rover, GSM 3,75 G, 555 channels, multicostellation, multiple frequency, Bluetooth and wifi), allowed to measuring the towers perimeter directly where it stands on ground. Local coordinates were provided by a Total station Geomax, Zoom 90 Robotic, remote control, accXess 10, surveying 1000 meters far objects with no prism, precision 5", Laser Class 3R, 658nm, prism-search automatic $360^{\circ}, 90 \mathrm{~km} / \mathrm{h} @ 100 \mathrm{~m}$, built-in Bluetooth for data transfer SR, Bt handle for LR and $360^{\circ}$ prism mounted on a 5 meter telescopic rod on bipod. The close range digital stereo-photogrammetry method creates a 3D surface model of the artifact, measurable and textured, in scale and referenced by local and/or geographic coordinates. By the identification and projection of multiple homologous points represented in more than two pictures adequately overlapped through the intersection of their homologous rays, it gets enough info to univocally reconstruct the whole point cloud object inside the Euclidean space and then to convert it into a mesh surface, even textured. 
About the aerial Photogrammetric survey, the planning of UAVs flight aimed at calculating some parameters for reaching the established result of the survey project. The Exposure time (seconds), the Frames per Second frequency (FPS-n $\%$ sec) and the Flight Speed (meters/sec) had to be calculated to grant the overlapping between shots to be at least of $60-80 \%$ in longitude (overlap) and $20-50 \%$ in latitude (sidelap). In parallel it was calculated the final survey model scale factor, computing each picture to be on the requested resolution, so defining the GSD (Ground Sample Distance) indicating the object real quantity (metric unit) included in each pixel, a datum depending on the flight height/distance from ground, that should be maintained constant and on the camera components configuration. So it worked the following proportion (1):

$$
\mathrm{d}: \mathrm{D}(\mathbf{G S D})=\mathbf{f}: \mathbf{H}
$$

where:

$$
\begin{aligned}
& \mathbf{d}=\text { pixel dimensions } \\
& \mathbf{D}=\text { object dimensions } \\
& \mathbf{f}=\text { focal distance } \\
& \mathbf{H}=\text { shooting height }
\end{aligned}
$$

For the Terrestrial near photogrammetry survey the same rules were applied, just substituting the flight height with the horizontal shooting distance from the object.

\subsection{The Integrated Applications Test}

The aim of this report is to evaluate the pros and cons resulting from the integration of different photogrammetry survey methods applied on some towers, selected for representing the sampling execution of low cost and short time consuming approaches, maintaining the requested architectural scale results.

3.3.1 Torre Jacova: Its stated that many medieval settlements were positioned nearby the consular routes that starting from Rome were passing through the countryside, so it is for this tower, laying at south of the $11^{\text {th }} \mathrm{km}$ of the Casilina, an ancient roman route directed toward Capua (Campania region). Maybe the tower is a little too far from downtown to be part of a casale and not of a more defensive castrum, however we see the presence of part of its redimen, underlining the role that this surrounding wall any how had of "first defence" (Esposito, 2005) from bandit's attacks and lootings of crops. The tower rises on top of a hill, ringed by vineyards without any visibility occlusion; this was the occasion to experiment applying the UAVs photogrammetry for the outside perimeter and the terrestrial for the inside, where no horizontal structure obstruction could prevent us from the intent of matching the internal with the external walls survey model. The local georeferencing of these two models was set by a motorized total station; previously 10 topographic nails have been materialized as base stations on ground, 4 at $18 \mathrm{~m}$ centrally respect to each façade and 4 diagonally, plus one near the entrance outside and one inside the tower. Then it followed the positioning of 17 $(20 \times 20 \mathrm{~cm})$ targets outside the survey area, fixed in vertical on some concrete poles delimiting the property, to be visible by any station in a number of at least 4 . Other 24 targets $(10 \times 10 \mathrm{~cm})$ were mounted on the outside walls and 16 inside, of which 4 were visually aligned with the outside station. For the geographical referencing of the model a GPS survey was performed, measuring on a levelled $2 \mathrm{~m}$ high extensible rod, 9 ground stations and 4 points corresponding to the building angles, so respecting the optimal distribution of GCPs around the focus area to be with a spacing of 1/5, 1/10 the UAV flight height (Harwin and Lucieer, 2012), even to help the accurate centering of the building inside the UAV flight survey project. The DGPS station in RTK mode used 18 satellites (10 GPS and 9 Glonass) to measuring the ground points with the prefixed 5 $\mathrm{cm}$ vertical and horizontal accuracy, a crucial datum for correctly georeferencing the model, it results also as a logic deduction if we compare the accuracy of the GPS mounted on drones (in meters) and that performed by ground DGPS antennas were the precision is centimetric in position as in elevation. The flight was executed by a quadcopter (Aeromax X4) shooting with a SONY alpha 5100, sensor APS-C CMOS $24.3 \mathrm{Mp}$, mounting a $16-50 \mathrm{~mm}$ lens (specs in previous text). Once inserted the GPS coordinates in Mission Planner SW, 5 flights were planned to obtain $70 \%$ overlap and executed with camera in landscape, speed of $2 \mathrm{~m} / \mathrm{s}$. The first flight was at $30 \mathrm{~m}$ height applied on a rectangular area, camera oriented at Nadir, focal length $50 \mathrm{~mm}$ (77mm eq.), FOV H $26,45^{\circ}$, V $17,73^{\circ}$, D $31,5^{\circ}$, aperture priority $\mathrm{f} / 5.6$, ISO 200 , keeping the exposure as automatic. Shooting time lasted 6,21 minutes, 61meters of flight in length, 130 shots, each one representing 9,10x13,75m in real, linear distance between shots $3 \mathrm{~m}$, so reaching a GSD $0,23 \mathrm{~cm}$, the single picture scale was $1 / 416,6$ and the final drawing scale $1 / 10$. The other 4 flights were in circle around a specified POI (Point of Interest), one at $+15 \mathrm{~m}$ altitude, camera pointing at 0 (ground level) of the tower center and the second at $+35 \mathrm{~m}$ altitude, camera pointed at $+20 \mathrm{~m}$; the third and fourth respectively at +15 and +20 altitude, pointing orthogonally towards the walls. The Focal length was $30 \mathrm{~mm}(45,9 \mathrm{~mm}$ equiv.) FOV H $42,78^{\circ}, \mathrm{V} 29,15^{\circ}$, D 50,36 ${ }^{\circ}$, Aperture priority set at $\mathrm{f} / 5$, ISO 200 . Each circular flight got 26 pictures with linear axel spacing 7-7,5m, so obtaining a GSD 0,39cm, 1 picture representing in real $23,5 \times 15,58 \mathrm{~m}$, single picture scale $1 / 653,6$, final drawing scale $1 / 20$. For the inside walls survey we applied the action camera Xiaomi YI 4K, sensor 1/2.3", 12 megapixels $(4000 \times 3000)$ CMOS, $2.66 \pm 5 \% \mathrm{~mm}$ Lens $(14 \mathrm{~mm}$, equiv.), on a $14 \mathrm{~m}$ high carbon rod and tripod, collecting 300 pictures, linear axel spacing $70 \mathrm{~cm}$ circa, GSD $0,154 \mathrm{~cm}$, in real each frame involves $6.16 \times 4.62 \mathrm{~m}$, single picture scale $1 / 250$, final drawing normed scale 1:5 (effect. 1:3). Internal and external surveys were elaborated in two separate chunks (Figure 6 ), producing dense point clouds of respectively 667,616 and 311,699 points, locally oriented by shared topographic survey points. The final whole model textured mesh has $1,866.153$ faces, 938,758 vertices (medium quality elaboration). After the georeferencing with GPS survey coordinates it has been saved in . kmz and .las formats (to import in Google Earth and into a GIS) and in .pdf (producing a pdf 3D were the navigable 3D textured scaled model can be measured and additional notes and observations can be added and shared).

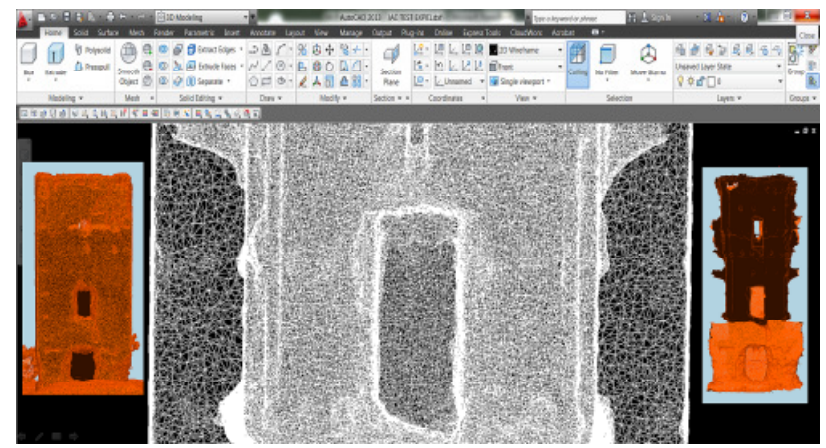

Figure 6. UAV outside and action-cam inside integrated mesh 
3.3.2 Torre Maggiore: It stands still in its original proportions at west of the $21^{\text {st }} \mathrm{km}$ of the Ardeatina route, 34 meters high and $7 \times 7 \mathrm{~m}$ wide, surrounded by a redimen ("Turris Maior cum claustro", Schiaparelli, 1902) internally flanked at east by another structure. The building, a square in plan with a 5 floors vertical distribution, has its ground entrance at north, aligned with a second one on the first floor, maybe the real safe entrance accessible by removable ladder, windows with marble frames lay aligned in upper floors. On the ground level a concrete cross vault divides it from the first floor to which a manhole is the only connection, aligned with the one still visible on the roof (maybe one on each floor was once present). The survey was realized in a very short time for the limited time access, using two UAVs, a DJI Phantom 4Pro (Ph4Pro) and a DJI Phantom4 ( $\mathrm{Ph} 4)$. To grant the accuracy in georeferencing the model, it is necessary in the final model not to keep the drone internal coordinates (exif data) but to apply an indirect georeferencing. So 12 control points were materialized on ground $(50 \times 50 \mathrm{~cm}$ Forex targets with spherical bubble were centered on $20 \mathrm{~cm}$ iron nails) and surveyed by a GPS antenna (Zenith 25 Geomax) in RTK mode, in WGS84 coordinates, setting a cut off angle of $15^{\circ}$, reaching a visibility from 11 to 18 GPS and GLONASS satellites, accuracy $5 \mathrm{~cm}$. The Ph4Pro, mounting a $8,8 \mathrm{~mm}$ lens (24mm equiv.) and a $20 \mathrm{Mp}$ camera sensor $(5472 \times 3648 \mathrm{pxl}-13,2 \times 8,8 \mathrm{~mm}-1 \mathrm{pix}=0,002412 \mathrm{~mm}$ FOV: $\mathrm{H} 73.7^{\circ}$, V $53.1^{\circ}$, D $84^{\circ}$ ) flew for Nadir shootings in two orthogonal directions at $43 \mathrm{~m}$ height (191shots, landscape $70 \%$ overlap) GSD $0.9 \mathrm{~cm}, 1$ picture representing in real $49,75 \times 33,16 \mathrm{~m}$, picture scale $1 / 1666,6$, final drawing normed scale 1/150 (effect. 1:123), enough for ground mesh model. One more flight was in circle at 40 meters altitude oblique view to POI at $35 \mathrm{~m}$. Cause this flight aimed at surveying adequately the vault extrados and the tower last floor, a detail otherwise unreachable, we calculated a $24 \mathrm{~mm}$ lens shooting at 10 meters flight distance from the tower top to get a picture scale $1 / 416,6$ and a final drawing normed scale $1 / 10$, so that selecting only pictures including vault and last floor details(among total of 180) it has been possible (keeping at first stage the exif data) to align them with those of the vertical walls taken as described below, keeping details we needed. More 293 pictures were taken by the $\mathrm{Ph} 4$, mounting a $3.5 \mathrm{~mm}$ lens and a $12.2 \mathrm{Mp}$ camera sensor, $(4000 \times 30000 \mathrm{pxl}-6,20 \times 4,62 \mathrm{~mm}-1 \mathrm{pix}=0,00155 \mathrm{~mm}-$ FOV: $\mathrm{H} 81.27^{\circ}, \mathrm{V} 44.33^{\circ}, \mathrm{D} 94.02^{\circ}$ ) flying in circle, cause of trees obstacles, at 10,20 and $30 \mathrm{~m}$ radial distance around central POI (point of interest indicated by its geographical coordinates) at 6 different heights from ground, GSD between $0,77 \mathrm{~cm}$ and $1,10 \mathrm{~cm}$, camera in frontal and in oblique view at different heights to get any detail. The whole of 473 pictures was aligned (Photoscan Pro, Agisoft.RU), using a single chunk and initially not removing the GPS data (EXIF) coming from the two GPS antennas on drones (no accuracy data provided), then all exif data were removed and substituted by the imported GPS data surveyed by Zenith25 GPS, producing a georeferenced and high, accurate dense point cloud of 5.312.509 points. The calculated mesh resulted regular, regardless of different resolution of the camera drones' sensors, lenses and flight distances, got 1,061,545 faces, 532,531 vertices, in medium quality selection, mild depth filtering, then textured with 4,096x4,096x8 (Atlas) (Figure 7).

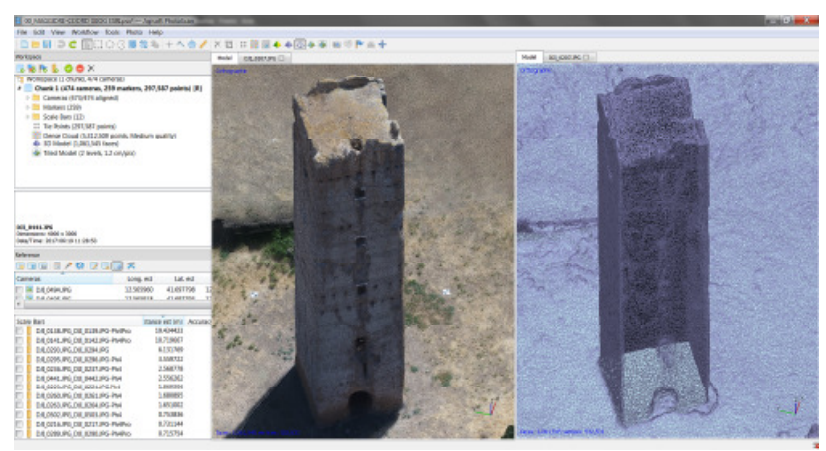

Figure 7. T. Maggiore. Final mesh, textured and wireframe

3.3.3 Torre Selce: facing the ancient Appia route just a few metres aside, this monument is characterized by a specific basement shape given by the pre-existence of a roman sepulchre on which the tower has been overbuild by the Astalli family, a redimen was present in origin and not visible anymore. To survey the high, star shaped basement the Canon 5D Mark III was mounted on a $5 \mathrm{~m}$ extensible rod with a $24 \mathrm{~mm}$ lens, shooting 480 pictures turning around the basement at 20 meters distance circa, each one representing in real $25,34 \times 16,89 \mathrm{~m}$, picture scale $1 / 833$, final normed drawing scale $1 / 50$ (effective $1 / 31$ ), resulting as aligned 411 of 480 . The following survey operation has been realized standing at the base of the tower walls at $+8 \mathrm{~m}$ altitude from ground, using Xiaomi YI $4 \mathrm{k}$ action cam on $14 \mathrm{~m}$ extensible rod. Of the full set of 328 photos, 326 were successfully aligned thanks to the positioning of Photoscan coded targets (12bit, $20 \times 20 \mathrm{~cm}$ ) and to the use of 60 topographic targets $(20 \times 20 \mathrm{~cm})$ widely distributed on ground around the tower and so included either in pictures taken from the hill's top (by YI 4k) as on those looking from ground upward (by Canon5D MIII) (Figure 8).

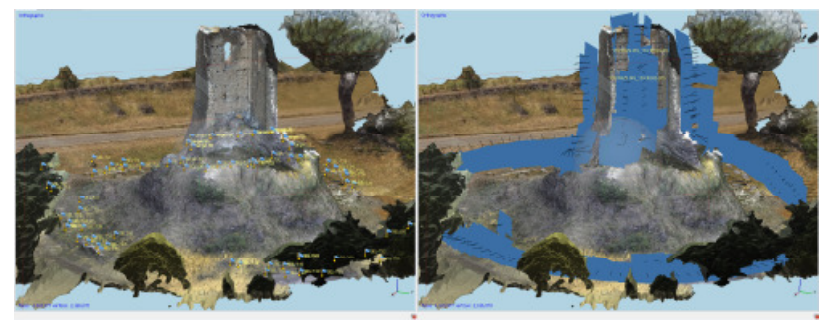

Figure 8. GPS and coded targets (left), shooting complex (right)

In any vertical stripe, along the external and internal walls till the top, respecting $1 \mathrm{~m}$ distance between shots centers, some were oriented in landscape frontal view and some in oblique downward, so to include even the top parts and the otherwise hidden details. It resulted useful taking some sets of pictures turning $180^{\circ}$ around each station, looking downward to the ground, to get all the $60(20 \times 20 \mathrm{~cm})$ targets distributed in the plain around the tower and later surveyed with GPS to geographically reference the model. In the alignment phase targets were identified in at least four pictures and the procedure worked as functional link for aligning in one single chunk Canon pictures and Yi action cam's. The one pixel real dimension is $1,4 \mathrm{~mm}$, picture real scale $1 / 429$, final normed drawing scale $1 / 10$ (effective 1/8,6). The dense point cloud resulting for the joined elaboration (in medium quality) of all pictures has, 24,225628 points, while the mesh got $4,349,977$ faces and 2,086,170 vertices. Considering the different drawing scale reached in each of the two pictures' groups, it is suggested to considering calculating each one separately till the final 
joining of resulting models, reachable by the common GPS points reference, so to grant a $1 / 10$ drawing scale on the full tower body, useful for future detailed analyses.

\section{THE DATABASE GIS INTEGRATION}

One of the targets of this research is the collection of all data inside a single GIS Platform. This operation is necessary to make spatial analyses and to share the results on a $2 \mathrm{D}$ and $3 \mathrm{D}$ WEBGIS environment. For this goal it was used the Esri Platform ArcGIS Pro with the 3D Analysis Extension for Desktop Analysis and the cloud ArcGIS Online environment (by Educational license).

The first workflow step has been the creation of the GIS database, by using the desktop ArcGIS Pro 2.0, the premier professional desktop GIS application from Esri; it allowed the visualizing, editing, and analyzing of any geographic data in both 2D and 3D. After having created projects, maps, layers, tools and more, several options helped to sharing the work by using the ArcGIS Online Esri cloud platform. The access to several Basemaps (Satellite, Street and others) allowed getting a Geographic reference to geolocate any of our multiple researchrelated geographic contents:

- Historical Maps

- Towers geolocations

- Surveys (Drone and other)

- Open data (local or WMS connections)

- $\quad$ Analysis (RLOS e LLOS)

The geodata was stored in the Esri Geodatabase, the native data structure for ArcGIS and the primary data format used for data editing and management. While ArcGIS works with geographic information in many GIS file formats, it is designed to work with and to leverage the capabilities of the geodatabase.

Geodatabases have a comprehensive information model for representing and managing any geographic information. This model is implemented as a series of tables, holding feature classes, raster datasets, and attributes. In addition, advanced GIS data objects add GIS behavior, rules for managing spatial integrity and tools for working with numerous spatial relationships of the core features, raster, and attributes.

Even Historical maps in .tif format were georeferenced through Ground Control Points, using online basemaps as reference and then stored as Raster dataset in the Geodatabase. The actual Hydrology network, we used (whether still present) to highlight the existence of water paths near almost any tower or casale, is provided by the Lazio Region authority as Open Data WMS (web map service) connection. The Digital Terrain Model (pixel resolution 20 meters) was provided by The ISPRA (Istituto Superiore per la Protezione e la Ricerca Ambientalehttp://www.isprambiente.gov.it/it/banche-dati) as Open Data.

This DTM was used to perform radial optical visibility analysis (RLOS-http://solutions.arcgis.com/defense/help/military-

tools/arcgis-pro/creating-radial-line-of-sight.htm) assuming an observer to be placed on towers top at $21 \mathrm{~m}$ and $35 \mathrm{~m}$ height. The Intervisibility analysis (LLOS http://solutions.arcgis.com/defense/help/military-tools/arcgispro/creating-linear-line-of-sight.htm) was also performed between towers, providing useful information to support the research, as it is possible to verify the theories related to the function of the towers relative to their surrounding area, involving properties extensions (when documented) by simulating their supposed original height.

Information about the photogrammetric surveys of towers made with the drone or through a vertical axis (described in the preceding chapters) has also been imported into the Geodatabase by converting the KMZ format.

The surveys carried out with the drone or through a camera mounted on a vertical axis (described in the preceding chapters) were also imported into the Geodatabase by converting the KMZ format.

These objects, within the Geodatabase, have been stored as three-dimensional Multipatch features, suitable for representing textured 3D meshes.

Regarding the Point Cloud survey models, ArcGIS Pro directly reads the LAS format and is able to use it as a 3D layer along with any other content by representing it with its original RGB colour components (Figure 9).

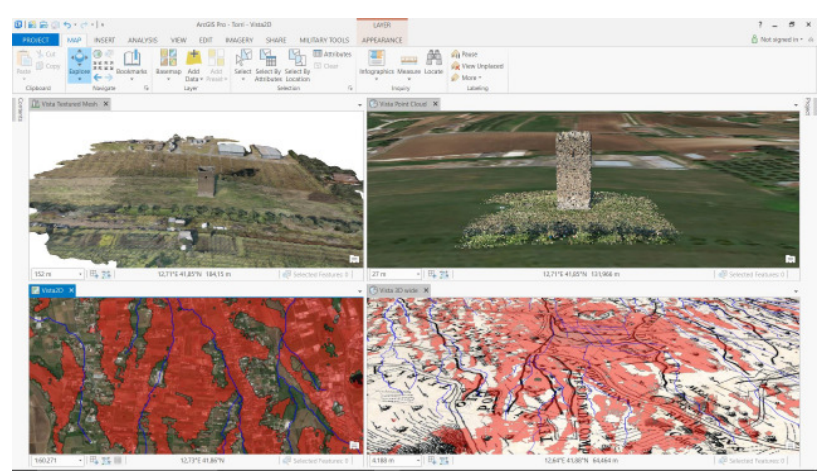

Figure 9. 2D/3D Geodatabase management with ArcGIS Pro

Following the creation and organization of the GIS, ArcGIS Pro is able to share the map data with the Esri ArcGIS Online cloud platform. ArcGIS Online is directly linked to ArcGIS Pro via web using enabled user connection.

ArcGIS Online is an online, collaborative web GIS that allows you host your GIS Data. Through this environment, it was possible to host all of the above mentioned survey data, creating custom maps and creating these 2D and 3D Web Apps that allow to viewing the results with a simple browser. These contents are hosted on the cloud and organized as REST services. In this environment, it has been possible to create 2D maps and 3D scenes using layers hosted in the ArcGIS Online cloud and also to connect to open source data such as OGC services or data made available by the user community. This was done with the Hydrography WMS (web map service), the free service provided by the Lazio Region.

Once created the 2D maps, it was possible to customize the data, to configure the fields with the associated information, and finally to customize the pop-ups.

After the making of map, custom web apps were created through some configurable templates, without having a specific knowledge of any development language. In the specific case, it has been used the "Basic Viewer" template, which contains the following functionalities: 
- $\quad$ Map Navigation (zoom an pan),

- Geocode addresses,

- Layer management (on/off)

- Legend

- $\quad$ Print

- Identify (according map configuration)

This application can be shared in public or private mode by a simple browser. Through ArcGIS Online, you can also share the individual layers within the community in public or by group with other users who have a subscription.

(http://ps-

esriitalia.maps.arcgis.com/apps/View/index.html?appid=90be39 a999904983b12a2e3e1d3dc294) (Figure 10).

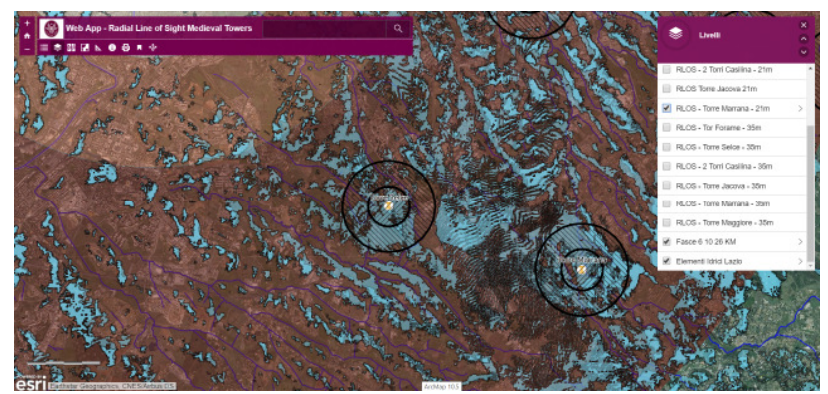

Figure 10. 2D Web App on ArcGIS Online

By using the Scene environment in ArcGIS Online, it is also possible to manage the three-dimensional content. In this environment, in addition to the $2 \mathrm{D}$ data displayed in draped mode above the ground (e.g. Historical Maps, Hydrography and Visibility Analysis), it was possible to load 3D Textured Mesh and Point Clouds of towers. Similarly to the 2D map is possible through this Scene, to create a navigable 3D web application that can be shared through links to other users. (http://psesriitalia.maps.arcgis.com/apps/3DScene/index.html?appid=08e 4d004a309494fa16500e853b38f7c) (Figure 11).

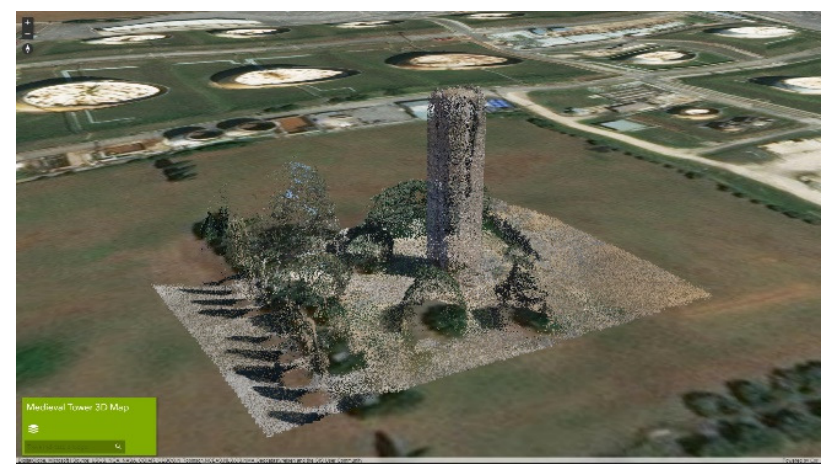

Figure 11.3D Web App on ArcGIS Online

\section{ACKNOWLEDGEMENTS}

The authors would like to gratefully acknowledge the support of: Agisoft (RU), Geomax Italy, Microgeo Italy, ESRI Italia, Andrea Menghini and Alessio Ronchi, graduating students.

\section{REFERENCES}

Carocci, S. and Vendittelli, M., 2004. L'origine della Campagna Romana. Casali, castelli e villaggi nel XII e XIII secolo. With essays of Esposito, D., Lenzi, M., Passigli, S.,
Roma, Società Romana di Storia Patria, (Miscellanea della Società romana di storia patria, 47), pp. VIII-376, 91 tavv. f.t.

De Rossi, G. M., 1969. Torri e castelli medievali nella Campagna romana, Roma, De Luca.

De Rossi, G. M., 1981. Torri medievali della campagna romana. Alla riscoperta di castelli e fortificazioni in un paesaggio ricco di millenari valori culturali, Roma, Newton Compton.

Esposito, D., 2005. Architettura e costruzione dei casali della Campagna Romana fra XII e XIV secolo, Roma, Società Romana di Storia Patria.

Grussenmeyer, P., Landes, T., Voegtle, T. and Ringle, K., 2008. Comparison methods of terrestrial laser scanning, photogrammetry and tacheometry data for recording of cultural heritage buildings. The International Archives of the Photogrammetry, Remote Sensing and Spatial Information Sciences, 37(B5), pp. 213-218.

Harwin, S. and Lucieer, A., 2012. Assessing the Accuracy of Georeferenced Point Clouds Produced via Multi-View Stereopsis from Unmanned Aerial Vehicle (UAV) Imagery. Remote Sensing, 4, pp. 1573-1599.

Lachat, E., Landes, T. and Grussenmeyer, P., 2017. First experiences with the Trimble SX10 scanning total station for building façade survey. The International Archives of the Photogrammetry, Remote Sensing and Spatial Information Sciences, 42(2/W3), pp. 405-412.

Marcelli, M., Schingo, G. and Lanna, R., 2014. Un GIS dei casali storici dell'Agro Romano. Supplemento al n ${ }^{\circ} 2-2014$ di GEOmedia-ISSN 1128-8132

Mouget, A. and Lucet, G., 2014. Photogrammetric archaeological survey with UAV. ISPRS Annals of the Photogrammetry, Remote Sensing and Spatial Information Sciences, 2(5), p. 251.

Murtiyoso, A., Grussenmeyer, P. and Freville, T., 2017. Close range UAV accurate recording and modeling of St-Pierre-leJeune neo-romanesque church in Strasbourg (France). The Int. Arch. Photogramm. Remote Sens. Spatial Inf. Sci., 42(2/W3).

Schiaparelli, L., 1901-1902. Le carte antiche dell'archivio capitolare di S. Pietro in Vaticano. Archivio della Società Romana di storia patria, 24 (1901), pp. 393-496; 25 (1902), pp. 273-354.

Shahbazi, M., Sohn, G., Théau, J. and Menard, P., 2015. Development and Evaluation of a UAV-Photogrammetry System for Precise 3D Environmental Modeling. Sensors, 15, pp. 27493-27524.

Stek, T. D., 2016. Drones over Mediterranean landscapes. The potential of small UAV's (drones) for site detection and heritage management in archaeological survey projects: A case study from Le Pianelle in the Tappino Valley, Molise (Italy). Journal of Cultural Heritage, 22, pp. 1066-1071.

Tomassetti, G., 1979-1980. La Campagna romana antica, medioevale e moderna. Nuova edizione aggiornata a cura di Luisa Chiumenti e Fernando Bilancia, 7 voll., Firenze. 